\title{
A TEORIA DO DIREITO REVISITADA PELO NOVO REALISMO: PLURALISMO E CONTINGENCIA
}

Diogo Bacha e Silva ${ }^{1}$

\section{Resumo}

O texto trabalha com uma interseção entre o novo realismo na vertente especulativa e a teoria do direito. Partindo da concepção de uma arrogância epistemológica e do conservadorismo epistemológico, é preciso sair da correlação entre o ser e o pensar para permitir que o direito adquira novos sentidos para além da subjetividade e da arbitrariedade que the é inerente. Ademais, a contingência do direito e o Grande Afora coloca por terra a busca pela essência, pela natureza, pelo conceito ou pelo o que é o direito. Pergunta que moveu toda a teoria do direito do século XXe XXI.

Palavras-chave: teoria do direito; realismo especulativo; contingência do direito.

\section{INTRODUÇÃO}

A visão que tem os juristas sobre seu próprio ofício, ao contrário de outros campos de sentido do mundo, tem dois importantes aspectos fundamentais: de um lado, o que chamamos de arrogância epistemológica, qual seja, a crença de que o Direito é um campo capaz de oferecer respostas para todos os problemas sociais, políticos e econômicos conjugado com a ideia de absoluta necessidade de existência do Direito. De outro lado, o que denominamos de conservadorismo epistemológico que significa que, mesmo oferecendo a necessidade do Direito, é uma área infensa à aquisição de novos conhecimentos, um campo no qual predomina a ideia de que tudo deve ser mantido como está e que qualquer mudança deve ser para manter o status quo. Mesmo a chamada

\footnotetext{
${ }^{1}$ Doutorando em Direito pela UFRJ, Mestre em Direito Constitucional pela FDSM, Professor Universitário do Curso de Direito da Faculdade de São Lourenço. E-mail: diogobacha@ig.com.br
} 
crítica do direito que pregaria uma transformação/emancipação do direito, acaba recaindo nestes pressupostos epistemológicos.

No entanto, é preciso indagar em que medida o pensamento sobre o direito pode ser infenso às novidades epistemológicas que cotidianamente novos campos de sentido adquirem. Assim, como seria pensar, por exemplo, os impactos que a teoria dos buracos de minhoca da física poderia desestabilizar os sentidos jurídicos, ou, ainda, como a ideia de aceleramento de partículas podem nos fazer repensar certos institutos jurídicos.

Em regra, a teoria do direito ainda trabalha com conhecimentos adquiridos pelo iluminismo e, quando muito, com as tendências da pós-modernidade de autores críticos do século XX ou a neurociências do século XXI. De qualquer maneira, tais pressupostos implicam na ideia de uma relativização, de uma incerteza, de uma fluidez do próprio direito.

A filosofia e o modo de pensar o mundo sofre um abalo com a obra de jovens filósofos do chamado novo realismo. Markus Gabriel e Quentin Meillausoux são os seus principais representantes. Uma vertente do realismo ontológico e uma vertente do realismo especulativo colocam em suspensão as teorias hermenêuticas, críticas, fenomenológicas e pós-estruturalistas. O pensamento filosófico sofre novos abalos e, pois, o Direito se limita apenas a ignorar os reflexos deste pensamento.

O objeto do presente texto é problematizar a própria teoria do direito e a forma como a mesma é pensada pelos juristas a partir do aporte das contribuições do novo realismo. Buscamos, assim, realizar uma aproximação acerca da teoria do direito mais tradicional e a discussão que é travada por jovens filósofos. A partir de então, é possível repensarmos e quem sabe contribuir para um deslocamento dos pressupostos epistemológicos tradicionais da arrogância e do conservadorismo.

Com efeito, tanto a teoria do direito como o novo realismo partem do seguinte problema: na teoria do direito, o grande questionamento que promove os caminhos metodológicos é saber o que é Direito? De outro lado, o novo realismo se abre a partir da resposta acerca de o que é o mundo? Qual pensamento sobre o mundo nós temos?

Com a aproximação poderemos perceber o quanto o pluralismo jurídico faz parte do próprio mundo do direito, e não só. O próprio mundo do direito aparece como uma contingência absoluta. Não há uma necessidade absoluta do Direito. Deve-se ter em mente que, portanto, a pergunta não é O que é Direito? A correta pergunta a abrir caminhos possíveis para se pensar o direito é "Whats is this Law"?

Um direito que é permeado pela sua própria contingência, eis nossos objetivos que permitirão esse caminhar teórico-reflexivo sobre teoria do direito. 


\section{A TEORIA DO DIREITO E O CAMINHAR METODOLÓGICO: O DEBATE DWORKIN E HART COMO PONTO DE PARTIDA PARA UM ESQUEMA CONCEITUAL CORRELACIONAL}

Herbert Hart inova as discussões sobre o questionamento acerca da verdadeira natureza do direito. Atrelado a uma filosofia analítica com as contribuições da virada linguística, especialmente do segundo Wittgenstein, o projeto teórico de Hart pretende conceber "o que é Direito" a partir da identificação de três problemas principais que guiarão o reconhecimento da verdadeira natureza do Direito. Pelo primeiro problema, Hart indaga a característica essencial partindo de Austin que no Direito não se corresponde a atos opcionais para o sujeito, mas sim atos obrigatórios. O segundo problema é diferenciar a ordem jurídica e ordem moral. Como se sabe, tanto direito quanto moral têm em seu núcleo substantivo a característica de que os comportamentos humanos já não são opcionais, mas obrigatórios. Em que medida se deve relacionar o direito da moral. Na terceira questão levantada por Hart, a questão é estabelecer como se configura a linguagem nas normas jurídicas e como se deve estabelecer a relação entre normas jurídicas e sua característica essencial de permitir a sanção e como ela se diferencia de outros comandos obrigatórios ${ }^{2}$. Os três problemas são: em que o direito se difere das ordens apoiadas em ameaças e como se relaciona com estes? Em que a obrigação jurídica se difere da mora e como se relacionam? O que são normas e até que ponto elas são os elementos essenciais do Direito?

Um dos elementos essenciais do Direito segundo Hart seria a constituição de uma ordem com ameaça de sanção. Para tratar deste aspecto primário do Direito, Hart utiliza do exemplo bem conhecido de Austin no seu Province of Jurisprudence Determined do assaltante armado que determina ao caixa do banco que the entregue determinada quantia em dinheiro. Diferentemente do comando do assaltante, o Direito seria constituído de ordens gerais amparadas por ameaças de sanção com uma obediência habitual ${ }^{3}$. Mas esta teoria fracassa, seja pelo fato de que os próprios comandantes da ordem também são obrigados a obedecer e há, também, normas que outorgam poderes jurídicos para decisões ou legislações e que não podem ser comparadas nas ordens apoiadas pelas sanções e, por último, existem normas que diferem em relação à sua origem, não sendo uma prescrição explícita ${ }^{4}$. A teoria de Austin, conforme observa Hart, descuida do aspecto ativo da criação do Direito. Deste modo, o Direito não poderia ser uma ampliação da situação do malfeito, ainda que um Direito primitivo 5 .

Por isso, a resposta ao "o que é Direito?" parte da constatação e da diferença entre hábito e normas

\footnotetext{
${ }^{2}$ HART, H.L.A. O conceito de direito. São Paulo: WMF Martins Fontes, 2009. p. 3-18.

${ }^{3}$ HART, H.L.A. O conceito de direito. São Paulo: WMF Martins Fontes, 2009. p. 26-33.

${ }^{4}$ HART, H.L.A. O conceito de direito. São Paulo: WMF Martins Fontes, 2009. p. 103-104.

${ }^{5}$ HART, H.L.A. O positivismo e a separação entre o Direito e a Moral. In: Ensaios sobre Teoria do Direito e Filosofia. Rio de Janeiro: Campus, 2010.p. 64
} 
sociais que fundará a noção que Hart têm sobre a natureza do direito. O ponto de vista interno e externo é a questão conceitual chave para se compreender a diferença entre o hábito de obediência e as regras. Utilizando a metáfora do jogo de xadrez, Hart parte da definição de que, mesmo sem saber as regras, um observador externo do jogo de xadrez pode constatar que cada jogador move a rainha de um modo padrão e, mais, que cada um dos jogadores tem determinado ponto de vista do quanto é acertado ou errado o movimento da rainha desta forma, ou seja, uma atitude crítico-reflexiva acerca da própria prática em que estão imersos, entendida como um elemento volitivo (reflexiva) e um elemento cognitivo (crítica) ${ }^{6}$. Na terminologia normativa, a crítica, o reconhecimento da justificação dessa crítica e a exigência de obediência à norma recebe a linguagem de "deve", "tem de", "certo" e "errado".

O ponto de vista interno faz com que um grupo determinado tenha uma aceitação da regra, modificando-o do mero hábito, pelo reconhecimento de que a aceitação, ainda que não espontânea, seja determinante para as regras. Este é o elemento volitivo-cognitivo que faz com que as normas sejam distintas do hábito de obediência. Essa é a aproximação que Hart faz de Wittgenstein, de que a linguagem não serve de mediação entre sujeito-objeto, mas uma relação pragmática de sujeito-sujeito.

O ponto de vista externo, embora não abordado com a devida profundidade, é a do observador que não aceita ele próprio as normas de conduta de determinado grupo social. $\mathrm{O}$ ponto de vista externo radical é aquele em que o observador apenas afirma como o grupo se relaciona com as normas de conduta, isto é, consiste apenas em registrar as regularidades do comportamento observável nas quais consiste basicamente na obediência às normas, sem fazer menção à forma como o grupo se relaciona com as normas a partir do ponto de vista interno?

Este é o núcleo pelo qual Hart trabalha a noção de obrigação e norma, fazendo uma crítica ao que ele denomina de teoria preditiva de Austin. Para Hart, uma teoria do direito não deve abdicar de nenhum ponto de vista. Essa é a ideia metodológica central de sua Teoria Analítica do Direito. Como um positivista jurídico, Hart apoia o ponto de vista externo não radical, ou seja, o que o teórico do direito deve fazer é descrever as regras jurídicas como são a partir do ponto de vista interno, independentemente se ele mesmo compartilha ou não as regras em seu aspecto interno ${ }^{8}$.

$\mathrm{Na}$ verdade, como bem explicitado por Neil MacCormick, o ponto de vista externo não radical que ele

\footnotetext{
${ }^{6}$ Em verdade, o aspecto interno das normas depende de uma atitude crítico-reflexiva de cada um sobre as normas: "Esse aspecto interno das normas pode ser ilustrado de uma maneira simples pela comparação com as regras de um jogo qualquer. Os jogadores de xadrez têm o hábito de mover a rainha da mesma maneira, hábito que um observador externo poderia registrar, sem nada saber sobre a atividade deles diante dos movimentos que fazem. Mas, além disso, esses jogadores têm uma atitude crítica e reflexiva diante desse padrão de comportamento: encaram-no como um padrão para todos os jogadores de xadrez. Cada um não apenas move ele próprio a rainha de certa maneira como tem também "um ponto de vista" sobre o quanto é correto e adequado que todos movimentem a rainha daquela maneira” (HART, H.L.A. O conceito de direito. São Paulo: WMF Martins Fontes, 2009.p. 75-76).

${ }^{7}$ HART, H.L.A. O conceito de direito. São Paulo: WMF Martins Fontes, 2009. p. 115-116.

${ }^{8}$ MACCORMICK, Neil. H.L.A.Hart. Trad. Claudia Santana Martins. Rio de Janeiro: Elsevier, 2010. p. 57-58.
} 
denomina de hermenêutico, pressupõe que alguém sem qualquer compromisso com o elemento volitivo próprio, procura descrever e reconhecer cognitivamente e avaliar o elemento volitivo. Deste modo, "(ele) pode entender as regras e standards pelo que são, mas ela mesma não os endossa ao enuncia-los e descrevê-los ou discutir sua correta aplicação" . Por isso, a teoria positivista de Hart se propõe como um positivismo metodológico.

Hart, então, não trata apenas as obrigações como refletindo a própria natureza do direito. Para ele, nas sociedades que ele denomina de primitivas, isto é, desprovida de poder legislativo, tribunais ou autoridades, vigora o que ele denomina de normas primárias de obrigação, ou seja, as normas que são encaradas apenas do ponto de vista interno ${ }^{10}$. Entretanto, aponta o teórico que tais sistemas são constituídos de defeitos que prejudicam a sociedade em que o mesmo aponta como a incerteza do conteúdo das normas, o caráter estático e, portanto, imodificável do conteúdo delas, não a sua adaptabilidade em relação ao progresso e a própria ineficiência dessas normas. Bastaria, então, suplantar as normas primárias de obrigação com as normas secundárias enquanto espécie diferente. As normas secundárias servem, pois, para transformar um mundo pré-jurídico ao jurídico.

Não são as normas secundárias elas mesmo uma norma de obrigações, mas referem-se a elas. Hart define, pois, como normas secundárias como normas aptas a superarem os defeitos do sistema jurídico em seu modo pré-jurídico em que só existe as normas primárias. Portanto, a norma de reconhecimento serviria como forma de superação da incerteza do direito. Do mesmo, a norma de modificação tem a utilidade de transpor o caráter estático do sistema jurídico primitivo. Por último, a norma de julgamento que remete à ineficiência e, alguns casos, pode também servir como norma de reconhecimento ${ }^{11}$. Essa união entre normas primárias e secundárias e seu relacionamento é que é a verdadeira natureza do direito, nada mais.

Não à toa, após as críticas de Dworkin, que Hart esboça um diálogo em que explicita ainda mais o caráter metodológico de sua teoria do direito. No seu pós-escrito, define sua teoria como geral e descritiva. Geral "no sentido de que não se vincula a nenhum sistema jurídico ou cultura jurídica específicos, mas busca fornecer uma descrição explicativa e elucidativa do direito como instituição social e política complexa, dotada de um aspecto regulatório" ${ }^{12}$. Já o caráter descritivo advém do fato de que Hart pretende uma teoria moralmente neutra e, deste modo, não procura justificar com quaisquer argumentos as formas e estruturas da descrição geral do direito ${ }^{13}$.

Dworkin e as críticas dirigidas a Hart sofisticaram e transformaram a teoria do direito. Sua primeira contraposição teórica é bem refletida já na primeira obra de Dworkin, Levando os Direitos a Sério, na qual o teórico levanta que não há apenas regras como padrões decisórios no Direito que, segundo Dworkin, estaria no

\footnotetext{
${ }^{9}$ MACCORMICK, Neil. H.L.A.Hart. Trad. Claudia Santana Martins. Rio de Janeiro: Elsevier, 2010. p. 65.

${ }^{10}$ HART, H.L.A. O conceito de direito. São Paulo: WMF Martins Fontes, 2009.p. 118-119.

${ }^{11}$ HART, H.L.A. O conceito de direito. São Paulo: WMF Martins Fontes, 2009. p. 122-128.

${ }^{12}$ HART, H.L.A. O conceito de direito. São Paulo: WMF Martins Fontes, 2009.p. 309.

${ }^{13}$ HART, H.L.A. O conceito de direito. São Paulo: WMF Martins Fontes, 2009.p. 309-310.
} 
centro do positivismo. A partir do caso Riggs vs. Palmer de $1889^{14}$, há evidentemente o reconhecimento de que a prática jurídica trabalha com questões de princípio. Há, pois, regras como questões de tudo ou nada, princípios como dimensão de peso e políticas que estabelecem objetivos a serem perseguidos e que não conduz a nenhum direito $^{15}$. Por meio dos princípios, Dworkin ataca uma questão central no pensamento positivista que é a discricionariedade judicial nos casos difíceis ${ }^{16}$. Os princípios, portanto, servem para pensar a integridade do direito.

A questão central que Dworkin critica sobre a própria concepção de direito é o que ele denomina de aguilhão semântico do positivismo. Num sentido, os teóricos do direito têm divergências teóricas profundas do direito. Na prática jurídica, pensa Dworkin, há divergências quanto aos próprios fundamentos do direito. Neste ponto, o positivismo encara a divergência teórica do direito como uma ilusão, apresentando o direito como uma mera questão de fato ${ }^{17}$.

O direito como mera questão de fato apoia-se no fato de que as divergências teóricas seriam apenas uma divergência empírica sobre o que as instituições jurídicas decidiram no passado e que, na verdade, a divergência teórica é sobre aquilo que o direito deveria ser. Os positivistas, dessa forma, apenas admitem a divergência empírica e não a interpretativa, a divergência teórica aponta para o fato de que a prática jurídica diverge sobre questões factuais, isto é, se proposições jurídicas são verdadeira ou falsas ${ }^{18}$.

Para Dworkin, então, uma concepção de direito deve justificar as nossas práticas jurídicas, sendo uma interpretação do que os juristas realizam, propondo-se mostrar à melhor luz o que justifica o uso da coerção por parte do Estado ${ }^{19}$. O convencionalismo fracassa em tal mister, em razão de que os juízes não se veem obrigados a aplicar o direito quando verificam em uma etapa pós-interpretativa que as extensões normativas das convenções passadas não têm consenso em sua literalidade ${ }^{20}$. Daí que os juízes não se sentem constrangidos a oferecer a resposta jurídica correta nestes casos.

No clássico capítulo VII do Império do Direito, Dworkin assume a perspectiva do direito como integridade. Utilizando-se de uma metáfora do juiz Hércules, o direito se constitui como uma prática

\footnotetext{
${ }^{14}$ DWORKIN, Ronald. Levando os direitos a sério. Trad. Nelson Boeira. São Paulo: Martins Fontes, 2007.p. 37 e ss.

${ }^{15}$ DWORKIN, Ronald. Levando os direitos a sério. Trad. Nelson Boeira. São Paulo: Martins Fontes, 2007.p. 42 e ss.

${ }^{16}$ Em sua réplica, Hart reconhece mesmo que houve uma falha ao não abordar profundamente dos princípios, no entanto, a adoção dos princípios para Hart não modificam a natureza do direito de que constituem em uma união de regras primárias e secundárias. Para ele, portanto, as normas de reconhecimento são o critério válido para a validade dos princípios e não um critério de conteúdo (HART, H.L.A. O conceito de direito. São Paulo: WMF Martins Fontes, 2009. p. 341-342).

${ }^{17}$ DWORKIN, Ronald. O império do direito. Trad. Jefferson Luiz Camargo. São Paulo: Martins Fontes, 2007.p. 10-12.

${ }^{18}$ DWORKIN, Ronald. O império do direito. Trad. Jefferson Luiz Camargo. São Paulo: Martins Fontes, 2007.p. 55.

${ }^{19}$ DWORKIN, Ronald. Oimpério do direito. Trad. Jefferson Luiz Camargo. São Paulo: Martins Fontes, 2007.p. 169.

${ }^{20}$ DWORKIN, Ronald. O império do direito. Trad. Jefferson Luiz Camargo. São Paulo: Martins Fontes, 2007.p. 160.
} 
interpretativa que deve captar à melhor luz os princípios de moralidade política da comunidade ${ }^{21}$.

Em síntese, um modelo interpretativo de decisão judicial que apresenta uma distinção entre o direito positivo, aquele encontrado nos livros, nas declarações da lei e das decisões passadas, e o direito como um todo que aceita a estrutura dos princípios de moralidade política, tomadas em conjunto como a melhor interpretação do direito positivo ${ }^{22}$.

Como ele mesmo diz, "[n]o direito como integridade, as proposições jurídicas são verdadeiras se constam, ou se derivam, dos princípios de justiça, equidade e devido processo legal que oferecem a melhor interpretação construtiva da prática jurídica da comunidade”23. O próprio direito contém ambições próprias e não propriamente o conceito de direito.

Este é o aspecto que faz com que Scott Shapiro venha a criticar a opção metodológica de Dworkin. Para ele, Dworkin desenvolve uma opção metodológica, é o que ele denomina de teoria da meta-interpretação. Considera que a meta-interpretação é aquela na qual não oferece uma metodologia específica para interpretar os textos jurídicos, senão uma metodologia para dizer qual metodologia é mais adequada ${ }^{24}$.

Em verdade, Shapiro tangencia um tema que aponta para a discussão que será travada a partir de pressupostos do novo realismo filosófico. Shapiro, em sua obra, recorta sua análise no questionamento do "o que é o direito" e não a pergunta familiar que todos se fazem de "qual é o direito". Para ele, então, sua abordagem é de natureza analítica, entendendo aqui como o exame dos fundamentos metafísicos do direito ${ }^{25}$.

Uma análise conceitual do Direito deve partir de suas propriedades internas, isto é, coletar verdades auto evidentes sobre a natureza de algo. Shapiro, portanto, enxerga o direito como uma ontologia social2 ${ }^{26}$.

De qualquer forma, Shapiro é um dos poucos que observam o esgotamento da correlação entre ser e pensar e aborda pequenos traços de possíveis consequências para tal. A grande discussão da teoria do direito está aferrada ainda a conceitos interpretativos e definições que remetem a natureza do direito ao pensar o direito.

\footnotetext{
${ }^{21}$ Dworkin (Uma Questão de Princípio. 2. ed. Tradução de Luís Carlos Borges. São Paulo: Martins Fontes, 2005. [Direito e Justiça].) compara essa tarefa a uma brincadeira infantil na qual cada participante é responsável por contar um única história. $\mathrm{Na}$ brincadeira, todos os participantes têm o mesmo tempo para participar e devem ouvir atentamente os antecessores para que uma linha coerência entre a história contada seja preservada. Não se trata de um "telefone sem fio", pois o objetivo da brincadeira não é repetir o que foi transmitido, mas desenvolvê-lo (evoluí-lo) da melhor forma, preservando os elementos essenciais do que inicialmente foi definido. Ou seja, se o primeiro a conta a história teve o objetivo de narrar um suspense, o participante da sequência deve ter a capacidade hermenêutica de perceber que ele não poderá transformar agora aquilo em uma comédia.

22 DWORKIN, Ronald. A Conferência Mccorckle de 1984: as ambições do direito para si próprio. Veredas do Direito, v. 4, nº 8, p. 9-31, Julho-Dezembro de 1997.p. 18-19.

${ }^{23}$ DWORKIN, Ronald. Oimpério do direito. Trad. Jefferson Luiz Camargo. São Paulo: Martins Fontes, 2007. p. 272.

${ }^{24}$ SHAPIRO, Scott. Legalidad. Trad. Diego Papayannis. Madri: Marcial Pons, 2014. p. 370.

${ }^{25}$ SHAPIRO, Scott. Legalidad. Trad. Diego Papayannis. Madri: Marcial Pons, 2014. p. 26.

${ }^{26}$ Sobre isso veja-se: PULIDO, Carlos Bernal. Austin, Hart e Shapiro: três concepções sobre o direito como entidade fundada em uma prática social. Revista Brasileira de Estudos Políticos, Belo Horizonte,n. 107, pp. 43-98, jul./dez. 2013.
} 


\section{A CORRELAÇÃo ENTRE O SER E O PENSAR E A AUSÊNCIA DE UM MÉTOdo REALISTA NA TEORIA DO DIREITO}

A sofisticação do realismo filosófico atual de autores como Markus Gabriel e Quentin Meillausoux simplesmente apaga a possibilidade de se pensar em um realismo jurídico, seja de cariz norte-americano ou escandinavo, redivivo. O pensamento do realismo norte-americano dos anos 1920 e 1930, bem explicado pela celebre frase de Holmes de que o direito nada mais é do que profecias sobre o que os tribunais farão na prática ${ }^{27}$, certamente significou um pesadelo no sentido de que os juízes criam o direito e os aplicam às partes sem qualquer critério objetivo e imparciais pré-existentes ${ }^{28}$. Já o realismo jurídico escandinavo, com Alf Ross como grande expoente, pretende explicar as categorias jurídicas em termos de fatos sociais utilizando a mesma lógica que a ciência empírica, utilizando, portanto, padrões de comportamento e sentimentos para a análise da validade das regras sociais.

Estes realismos nada mais são do que uma variante do pensamento correlacionista, chamado de um realismo ingênuo por Quentin Meillasoux ${ }^{29}$. O correlacionismo é o pensamento moderno que se firmou após Kant na qual não se permite o pensar e o ser de modo independente, não se permite pensar estes termos isoladamente ${ }^{30}$. Toda a pretensão de pensar a esfera da subjetividade e da objetividade de forma independe é refutada pelo correlacionismo.

Após Kant, que tornou a questão da substância o problema central da filosofia, a filosofia se centrou em pensar a ideia, o indivíduo, o átomo, Deus, tornando assim um pensamento entre da correlação sujeito-objeto, noético-noématico, sem pensar em sua correlação mais originária. A pergunta assim que deveria ser feita: não é qual o justo substrato? Mais: qual é o justo correlato?

$\mathrm{Na}$ verdade, o correlacionismo impede que possamos sair do pensamento entre os objetos e a linguagem, entre o ser e o pensar. O realismo especulativo de Quentin Meillasoux pretende realizar uma crítica ao correlacionismo com a ciência de que se trata de uma crítica contraditória ou performativa, isto é, que pretende sair do mundo, porém estando nele e falando sobre ele ${ }^{31}$.

\footnotetext{
${ }^{27}$ HOLMES JÚNIOR, Oliver Wendell. The common law. New York: Dover, 1991.

${ }^{28}$ HART, H.L.A. A teoria do direito norte-americana pelos olhos ingleses: o pesadelo e o nobre sonho. In: Ensaios sobre Teoria do Direito e Filosofia. Rio de Janeiro: Campus, 2010. p. 142.

${ }^{29}$ MEILLASSOUX, Quentin. Après la finitude: essai sur la necessite de la contingence. Paris: Éditions du Seuil, 2006.p. 18.

${ }^{30}$ MEILLASSOUX, Quentin. Après la finitude: essai sur la necessite de la contingence. Paris: Éditions du Seuil, 2006.p. 18.

${ }^{31}$ MEILLASSOUX, Quentin. Contingencia y absolutización de lo uno. Nombres, Revista de Filosofía, No. 25, nov. 2011, pp. 171 206.
} 
É importante ter que a crítica de Meillasoux não implica a dominação da filosofia da representação, eis que as críticas à filosofia da representação, tais como a virada linguística, as teorias hermenêuticas, o pósmodernismo, etc., não representam uma ruptura com o correlacionismo. De fato, as críticas a filosofia da representação não apresentam um pensamento mais originário, já que significa apenas um retorno ao dogmatismo ${ }^{32}$.

O realismo especulativo de Quentin Meillasoux pretende sair da contradição performativa oferecendo uma contribuição interpretativa dos enunciados ancestrais em termos de um antirrealismo específico e também constituindo um realismo não ingênuo capaz de fundar um valor absoluto de descrição da realidade científica da ancestralidade.

As ciências experimentais oferecem questões importantes através da datação, inclusive eventos anteriores à própria consciência. Assim, por exemplo, a origem do universo data de aproximadamente 13,5 milhões de anos, a formação da terra de aproximadamente de 4,45 milhões de anos, a origem da vida terrestre em 3,5 milhões de anos e a origem do homem em aproximadamente 2 milhões de anos ${ }^{33}$. Essas datas se tornaram absolutas na medida em que, a partir da década de 1930, foram criados instrumentos capacitados para aferir a duração dos objetos medidos.

Toda realidade anterior à aparição do homem na terra é denominada por Quentin Meillasoux de ancestral. Um archifossile são materiais que permitem que a experiência da datação de ancestrais seja realizado, dando origem a estimação do tempo do referido objeto. A experiência da datação demonstra que o pensamento correlacionista é o a forma de pensar a vida depois de Kant.

A ancestralidade é um problema filosófico e que repercute na esfera do pensamento sobre o mundo. $\mathrm{O}$ problema é colocado pelo pensamento do realismo especulativo não para resolve-lo, mas para colocá-lo de forma rigorosa e pensar que é possível sair do esquema correlacional.

Por exemplo, a matemática consegue pensar um mundo para além da existência do homem, pensando um Grand Dehors, um grande fora do ser e do pensar. O archefóssil nos convida a pensar como ocorreu essa passagem furtiva do pensamento que não permite que saia da autorreferencialidade, a fim de permitir-nos pensar no objeto em si e no que somos ou não somos.

A questão é sair do correlacionismo. Nisto, Quentin Meillasoux pretende abordar um absoluto que a realidade absolutamente separada do sujeito que pode ser pensada pelo sujeito. Muito embora possa parecer à primeira vista uma relação contraditória, ela é apenas especulativa. Dois pontos são importantes: o primeiro já mencionado é o problema da ancestralidade e o segundo é o problema da facticidade. Por este último, Quentin

\footnotetext{
${ }^{32}$ MEILLASSOUX, Quentin. Après la finitude: essai sur la necessite de la contingence. Paris: Éditions du Seuil, 2006. p. 22.

${ }^{33}$ MEILLASSOUX, Quentin. Après la finitude: essai sur la necessite de la contingence. Paris: Éditions du Seuil, 2006.p. 24.
} 
Meillassoux quer dizer que não é possível falar contra a correlação exceto dentro da correlação ${ }^{34}$.

Pelo correlacionismo, o realismo especulativo aduz que se trata de um pensamento que não permite pensar o ser independentemente do próprio pensar. Não temos acesso nunca a um objeto e não se pode nunca sair de seu próprio pensamento ${ }^{35}$. Ademais, o correlacionismo não acredita no absoluto, por isso há uma relação de correlato de nós mesmos com o mundo. O pensamento correlacionista, portanto, acredita que é impossível um realismo ingênuo.

Assim, o ser e o pensar se relacionam de tal modo que é impossível pensar sem o ser ou o ser sem o pensar. Há uma desabsolutização do pensamento. Pensar quando não há o pensamento, eis a proposta do realismo especulativo.

Para tanto, necessário uma observação: o pensamento é sempre contingente, isto é, sabendo que é possível pensar um ser sem o pensamento, tal qual o exemplo dos objetos ancestrais. O pensamento, portanto, só existe nos seres viventes que são mortais por natureza, ou seja, pensamentos que podem morrer junto com seu portador. E, também, o próprio homem pode desaparecer da face da terra sem que altere a realidade circundante. O realismo propõe, então, um projeto de ontologia na medida em que o pensamento é realmente contingente e que o ser poderia subsistir tal como é, inclusive sem pensamento algum ${ }^{36}$.

As chaves centrais do correlacionismo foram sem dúvida a consciência e a linguagem. Qualquer acesso à exterioridade deveria se fazer por meio de palavras que, no entanto, não eram constituídas de palavras. A consciência mesmo está voltada para dados que estão no mundo, mas não nela mesmo. Este exterior, portanto, está confinado dentro de si mesmo. O Grande Afora deve pensar em sair do dogmatismo. Pensar independentemente do pensamento.

A teoria do direito não destoa do esquema correlacional. Em primeiro lugar, as teorias descritivas do direito tal qual apresentada por Hart, por exemplo, pretende metodologicamente encontrar o conceito do direito a partir da reunião entre regras primárias e secundárias. O ser do direito é encarado sob o mundo do direito. As regras fazem parte do campo de sentido do direito. No realismo ontológico de Markus Gabriel, os campos de sentido são os locais pelos quais determinado objeto se manifesta. Assim, portanto, o homicídio só aparece no campo de sentido do direito como sendo a infração penal pela provocação da morte de outrem.

O direito é uma espécie de construtivismo. Encaramos o direito como as interpretações que se fazem dos fatos e não da própria noção de que os fatos existem por si mesmos. A existência de algo está pré-condicionada

\footnotetext{
${ }^{34}$ MEILLASSOUX, Quentin. Time without becoming. Mimesis Intl., 2014.

${ }^{35}$ MEILLASSOUX, Quentin. Contingencia y absolutización de lo uno. Nombres, Revista de Filosofía, No. 25, nov. 2011, pp. 171 206.p. 177.

${ }^{36}$ MEILLASSOUX, Quentin. Contingencia y absolutización de lo uno. Nombres, Revista de Filosofía, No. 25, nov. 2011, pp. 171 206.p. 179.
} 
pelo campo de sentido em que aparece e tal é, portanto, a interpretação que se faz deste fato, sem que possa ser um fato em si mesmo ${ }^{37}$.

Assim, a teoria do direito só pensa a natureza do direito a partir da interpretação dos fatos do direito, a partir das interpretações do ser. O direito seria uma relação entre nossa interpretação sobre as regras primárias e as regras secundárias ou, ainda, o direito é uma prática interpretativa à melhor luz dos princípios de uma determinada comunidade política.

O direito acaba sendo, pois, um conjunto de referências de sentidos, em amplo aspecto um construtivismo entre o ser e o pensar, entre as referências das fontes do direito, do ser do direito, com nossas interpretações. Neste aspecto, pensar o direito é sempre um pensamento relativo, pensamento arbitrário sobre o sentido jurídico imersos em uma relação de poder em que a interpretação é produzida pela plurirreferencialidade ${ }^{38}$.

Este esquema correlacionista da teoria do direito não permite pensar o direito para além da relativização. O direito jamais foi pensado como objeto em si mesmo, sendo sempre uma relação subjetiva, ou seja, daquilo que o pensamento acredita ser o direito. A teoria do direito, portanto, só conseguiu construir arbitrariedade e uma forte relação de poder em que se escancara a autoridade daqueles que constroem o pensamento jurídico e aqueles que são submetidos a ele.

Não há um dado absoluto e fundamental que diga que o direito seja necessário em nossas sociedades. Fomos levados a acreditar pelo pensamento correlacional que o direito é um dado necessário sem o qual não seria possível a vida comunitária e, mais, que as conquistas civilizacionais são sempre creditadas à própria existência do direito e a forma como o pensamos.

Abrir mão do esquema correlacional do direito é possibilitar o Grande Fora, o além do pensar, de tal forma a permitir críticas ao próprio direito. Por óbvio, como no realismo especulativo, não é possível pensar além do correlacionismo sem estar dentro do correlacionismo. Por isso, as construções teóricas do direito tais como as importantes abordagens de Hart e Dworkin permitem que se pense a própria contingência do direito.

\section{POR UMA TEORIA DO DIREITO ESPECULATIVA: PLURALISMO E CONTINGENCIA}

A teoria do direito sempre buscou indagar qual a relação do direito com a moral? Quais as características

\footnotetext{
${ }^{37}$ GABRIEL, Markus. Por que o mundo não existe. Rio de Janeiro: Ed. Vozes, 2015. p. 67-69.

${ }^{38}$ SIMIONI, Rafael. Direito, interpretação e correlacionismo: uma leitura do realismo especulativo de Quentin Meillassoux. Argumenta Journal Law, Jacarezinho - PR, Brasil, n. 26. p. 15-36.
} 
do direito que o fazem uma prática social distinta das demais? $\mathrm{O}$ direito prescinde da noção de autoridade? $\mathrm{O}$ direito é definitivamente posto pelo Estado? Há alguma relação entre direito e justiça? Qual o método que os juristas devem utilizar para obter respostas dentro do direito? O direito é capaz de revelar ou desvelar a verdade? É o direito uma técnica ou uma filosofia? Seus métodos se assemelham aos utilizados pelas ciências chamadas duras?

A teoria do direito e a filosofia do direito deve partir de um realismo, principalmente na vertente especulativa. Se, portanto, não é possível encontrarmos um dado archefóssil jurídico, algo como uma lei, uma decisão, uma constituição antes da própria vida, para além da existência humana ou independentemente da vida humana, não implica que não se possa pensar o direito em uma realidade especulativa.

Pensar o direito para além do correlacionismo significa encarar que há uma plausibilidade de que o próprio direito não é uma realidade ontológica fundamental da humanidade. Deve-se pensar na desabsolutização do direito. Seria, pois, o direito como algo imprescindível para a vida ou apenas um dado contingente da existência ou, ainda, para dizermos com o realismo ontológico, apenas um campo de sentido fornecido pelo mundo?

A contingência é o único critério que se permite pensar fora do correlacionismo. $O$ direito não teria uma razão inerente, senão que sua razão seria apenas a contingência. A tão decantada ideia de que onde há sociedade há direito apenas esconde um esquema de pensamento correlacional e permite um subjetivismo sob as máscaras da objetividade. Ninguém pode afirmar, ao certo, se o direito existia ou não antes da existência da humanidade.

Alguns objetariam, pois, que o direito é criado para e pelo homem, daí que seria impensável a existência do direito sem a humanidade. Essa, no entanto, não é a realidade, nem mesmo do pensamento do direito. Basta, por exemplo, lembrarmos dos fundamentos da própria noção de Direito Natural ao gosto de Santo Agostinho. Se, pois, considerar que o direito é emanação da divindade, então é possível falar que há uma existência jurídica independentemente dos homens.

De outro lado, poderíamos pensar no direito em um outro planeta. Apenas por hipótese, é possível afirmar que, além do óbvio questionamento sobre a possibilidade de seres viventes em Marte, seria factível afirmar que não só aqui como lá também existem normas, tribunais, leis, países, organizações internacionais, contratos, demandas judiciais, arbitragem, etc.?

Pelo pensamento não realista do direito, seria imperioso aduzir que, se os substratos da vida marciana são os mesmos que a vida terrestre, então o direito é um mecanismo necessário para a existência comunitária da vida alienígena. Ainda que se pense, pois, que a vida marciana não tem os mesmos pressupostos organizacionais que a vida terrestre, é de se admitir que o direito também existe lá.

E por qual razão também não admitiríamos, por exemplo, que se houver uma vida para além deste plano, tal qual preconizada por Platão, seria imperioso que o direito também existisse, já que a mesma lógica deve presidir 
com a vida material. Não é bem assim, entretanto.

Não sabemos ao certo nem mesmo quando o direito surgiu em nossa sociedade. É provável e bem plausível que ele não tenha existido em todas as sociedades e em todos os tempos. Basta lembrar, pois, que as pesquisas antropológicas na área do direito aduzem a existência de estruturas e culturas jurídicas homomorfas em que, embora possa até mesmo existir mecanismos de resolução de querelas sociais, não é possível dizer, senão com um grande esforço de aproximação, que essas culturas fariam parte do sentido do direito, tal como nós o conhecemos $^{39}$.

É preciso repensar, portanto, a lógica do direito como meio de pensamento, prática social, ordem justa, prática interpretativa que apenas demarcaria um contínuo processo de evolução do homem. Há, portanto, uma necessidade de se pensar o direito para além da correlação. Para tanto, o direito precisa ser entendido como pluralismo e como contingência em uma relação conjugada.

Em regra, a plurivocidade do termo pluralismo tende a albergar um grande número de propostas teóricas distintas e com caráter absolutamente contraditórias. A marca que define o pluralismo seria, pois, a possibilidade de existência de um direito para além do direito estatal, oficial.

De algum modo, a expressão do pluralismo que se deve pensar a partir do realismo especulativo é de uma pluralidade de práticas, experiências, entre conflitos e consensos sociais, que fazem parte de um universo de sentido que é caracterizado como jurídico. Deste modo, todas as experiências e práticas sociais são constituídas em fundamentos frágeis, prescindíveis para a vida, ou seja, sua única essência é ser contingente.

Ora, o sentido teórico de pluralismo empregado por Antonio Carlos Wolkmer é representativo daquilo que a teoria do direito especulativa deve adotar: "a multiplicidade de práticas jurídicas existentes num mesmo espaço sócio-político, interagidas por conflitos ou consensos, podendo ser ou não oficiais e tendo sua razão de ser nas necessidades existenciais, materiais e culturais" ${ }^{\prime 4}$.

Romper com a lógica do direito subjetivo significa adotar pressupostos filosóficos do realismo especulativo, em especial o caráter contingencial do próprio direito. É preciso pensar que o direito não tem uma essência ou um conceito que the esteja subjacente, senão que é um campo de sentido construído de forma absolutamente arbitrária e de acordo com a necessidade e que, dessa forma, tem um prazo de validade, mesmo que não se possa dizer quando haverá de acabar esse campo de sentido e mesmo se haverá a substituição do direito por outra forma de enxergar os conflitos, a autoridade, a obrigação, as normas, a moral, as instituições, etc.

\footnotetext{
${ }^{39}$ RUDE-ANTOINE, Edwige; CHRÉTIEN-VERNICOS, Genivévi (Coords.). Anthropologies et droits. Paris: Dalloz, 2009.

${ }^{40}$ WOLKMER, Antônio Carlos. Pluralismo jurídico: fundamentos de uma nova cultura do direito.2.ed. São Paulo: AlfaOmega,1997.p. 195.
} 


\title{
CONSIDERAÇÕES FINAIS
}

Nosso objetivo de repensar os fundamentos teóricos do direito e, em especial, para romper com aquilo que denominados de arrogância epistemológica e o conservadorismo epistemológico do direito nos levou a entrelaçar o pensamento do novo realismo filosófico com a teoria do direito.

Os teóricos do direito sempre pensaram a relação do direito de forma a correlacionar o ser do direito e o pensar do direito, sem indagar se existe um direito fora deste esquema relacional. Até mesmo os sofisticados pensamentos da teoria do direito de Hart e Dworkin demonstram que o pensamento jurídico está atrelado a um subjetivismo latente, ainda que escamoteado na objetividade de uma possível intersubjetividade.

O próprio olhar para as fontes do trabalho do direito não serve para se conferir qualquer objetividade, senão que há uma plurirreferencialidade entre as fontes e a interpretação das fontes que chegaria até o infinito.

Deste modo, o realismo especulativo é um pensamento inovador no âmbito filosófico que serve para pensarmos o direito e possibilitar que se pense fora da correlação. Basta ver que o direito é contingente e plural e que não há um grande ser jurídico que deverá ser infinito para a existência da humanidade.

\section{THE THEORY OF LAW REVISITED BY THE NEW REALISM: PLURALISM AND CONTINGENCY}

\begin{abstract}
The text works with an intersection between the new speculative realism and the theory of law. Starting from the conception of epistemological arrogance and epistemological conservatism, it is necessary to get out of the correlation between being and thinking to allow the law to acquire new meanings beyond subjectivity and the arbitrariness inherent in it. In addition, the contingency of law and the Great Afora puts the quest for essence, for nature, for concept or for what is right. Question that moved the entire theory of law of the twentieth and twentyfirst century.
\end{abstract}

Keywords: theory of law; speculative realism; contingency`s law. 


\section{REFERENCIAS}

DWORKIN, Ronald. A Conferência Mccorckle de 1984: as ambições do direito para si próprio. Veredas do Direito, v. 4, no 8, p. 9-31, Julho-Dezembro de 1997.

Levando os direitos a sério. Trad. Nelson Boeira. São Paulo: Martins Fontes, 2007.

O império do direito. Trad. Jefferson Luiz Camargo. São Paulo: Martins Fontes, 2007.

Uma Questão de Princípio. 2. ed. Tradução de Luís Carlos Borges. São Paulo: Martins Fontes, 2005.

GABRIEL, Markus. Por que o mundo não existe. Rio de Janeiro: Ed. Vozes, 2015.

HART, H.L.A. A teoria do direito norte-americana pelos olhos ingleses: o pesadelo e o nobre sonho. In: Ensaios sobre Teoria do Direito e Filosofia. Rio de Janeiro: Campus, 2010.

O conceito de direito. São Paulo: WMF Martins Fontes, 2009.

O positivismo e a separação entre o Direito e a Moral. In: Ensaios sobre Teoria do Direito e Filosofia. Rio de Janeiro: Campus, 2010.

HOLMES JÚNIOR, Oliver Wendell. The common law. New York: Dover, 1991.

MACCORMICK, Neil. H.L.A.Hart. Trad. Claudia Santana Martins. Rio de Janeiro: Elsevier, 2010.

MEILLASSOUX, Quentin. Après la finitude: essai sur la necessite de la contingence. Paris: Éditions du Seuil, 2006.

Contingencia y absolutización de lo uno. Nombres, Revista de Filosofía, No. 25, nov. 201 1, pp. 171-206.

Time without becoming. Mimesis Intl., 2014.

PULIDO, Carlos Bernal. Austin, Hart e Shapiro: três concepções sobre o direito como entidade fundada em uma prática social. Revista Brasileira de Estudos Políticos, Belo Horizonte,n. 107, pp. 43-98, jul./dez. 2013.

RUDE-ANTOINE, Edwige; CHRÉTIEN-VERNICOS, Genivévi (Coords.). Anthropologies et droits. Paris: Dalloz, 2009. 
SHAPIRO, Scott. Legalidad. Trad. Diego Papayannis. Madri: Marcial Pons, 2014.

SIMIONI, Rafael. Direito, interpretação e correlacionismo: uma leitura do realismo especulativo de Quentin Meillassoux. Argumenta Journal Law, Jacarezinho - PR, Brasil, n. 26. p. 15-36.

WOLKMER, Antônio Carlos. Pluralismo jurídico: fundamentos de uma nova cultura do direito.2.ed. São Paulo: Alfa-Omega,1997.

Trabalho enviado em 29 de junho de 2018

Aceito em 06 de agosto de 2018 